This item was submitted to Loughborough's Research Repository by the author.

Items in Figshare are protected by copyright, with all rights reserved, unless otherwise indicated.

\title{
Evaluating the use of functionally graded materials inserts produced by selective laser melting on the injection moulding of plastics parts
}

PLEASE CITE THE PUBLISHED VERSION

PUBLISHER

Professional Engineering Publishing / @ IMechE

VERSION

VoR (Version of Record)

LICENCE

CC BY-NC-ND 4.0

\section{REPOSITORY RECORD}

Beal, V.E., Poonjolai Erasenthiran, Carlos Henrique Ahrens, and Phill M. Dickens. 2019. "Evaluating the Use of Functionally Graded Materials Inserts Produced by Selective Laser Melting on the Injection Moulding of Plastics Parts". figshare. https://hdl.handle.net/2134/4718. 
This item was submitted to Loughborough's Institutional Repository (https://dspace.lboro.ac.uk/) by the author and is made available under the following Creative Commons Licence conditions.

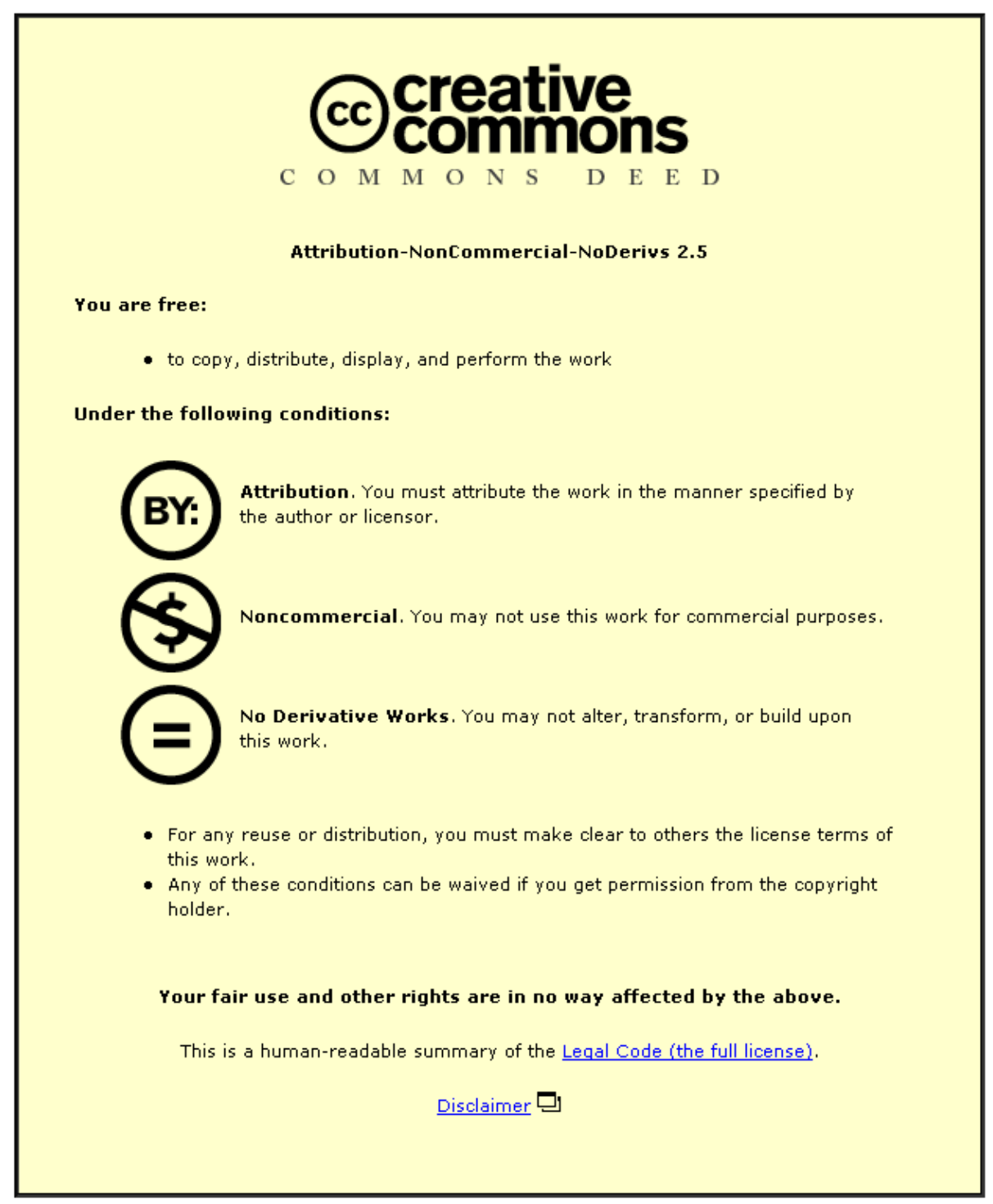

For the full text of this licence, please go to: http://creativecommons.org/licenses/by-nc-nd/2.5/ 


\title{
Evaluating the use of functionally graded materials inserts produced by selective laser melting on the injection moulding of plastics parts
}

\author{
V E Beal $^{1 *}$, P Erasenthiran ${ }^{2}$, C H Ahrens ${ }^{1}$, and P Dickens ${ }^{2}$ \\ ${ }^{1}$ Universidade Federal de Santa Caterina, Florianópolis, Brazil \\ ${ }^{2}$ Wolfson School of Mechanical Engineering, Loughborough University, Loughborough, UK
}

The manuscript was received on 19 October 2006 and was accepted after revision for publication on 9 March 2007.

DOI: 10.1243/09544054JEM764

\begin{abstract}
The demand for productivity and shape complexity on the injection moulding industry necessitates new research to improve tool design, material, and manufacturing. A research field is the development of functionally graded materials (FGMs) to build injection moulds. For example, moulds built with the FGMs technique can have distinctive regions with higher heat conduction. Higher rates of heat transfers from thicker regions of the injected part can be useful to produce better and cheaper injection moulded polymer parts. It is possible to obtain moulds with differential conductivity by adding locally, during the fabrication of the mould, copper to the mould base material such as tool steel. In this work, an investigation into the effect of FGM copper $(\mathrm{Cu})$-tool steel mould insert over polymer injected parts is presented. The work is divided in two parts: a numerical thermal analysis comparison between $\mathrm{Cu}$-tool steel graded and tool steel inserts and an injection moulding experiment with comparisons between mould surface temperature and degree of crystallinity of polypropylene parts. The numerical model was used to compare different behaviour of the mould heat transfer according to the mould insert material. Thereafter, a bolster was built to hold FGMs and tool steel inserts obtained by a selective laser fusion process. Polypropylene was injected over the inserts to compare with the numeric results. To observe the effect of the cooling rate in the polypropylene parts using the graded inserts, the degree of crystallinity of the parts was measured by differential scanning calorimetry (DSC) test. The temperature of the mould was also evaluated during the injection cycles. The results showed that the graded $\mathrm{Cu}$-tool steel inserts tested had lower capacity to store heat energy. As $\mathrm{Cu}$ was added to the tool steel, the mixture proved to transfer heat more efficiently but it had less capacity to absorb heat.
\end{abstract}

Keywords: functionally graded materials, injection moulding, rapid manufacturing, polypropylene crystallinity

\section{INTRODUCTION}

The benefit of injection moulded parts depends on three general aspects: tool cost, injection moulding raw material, and productivity of the tool. This trio makes it difficult to change part/mould design without affecting productivity and material. Hence,

*Corresponding author: Engenharia Mecânica - CIMJECT, Universidade Federal de Santa Catarina, Caixa Postal 476, Campus Universitário - Trindade, Florianópolis, Santa Catarina 88040-900, Brazil. email: valterbeal@gmail.com durability of the tool, productivity, and costs must be achieved by the optimal material raw selection and part and mould designs [1]. Unfortunately, there are restraints that make it difficult to find the best compromising solution. As the complexity of a modern injection mould is high, the mould designer's concern is how to solidify the part without causing distortions and keeping the mould with high rates of parts produced per hour. A complex channels network is designed to enable cooling liquid to extract the heat from the mould. The design of the channels is difficult as it is necessary to keep the ejection system in place. 
Ejector pins, slides, and air stream gates are used to eject the part from the mould cavity avoiding marks in the aesthetic side of the part. Depending on the complexity and shape of the part, the space left by the cooling system is small and it is not feasible to manufacture without leaving marks in the mould impression. In many cases, when the heat extraction equilibrium for homogeneously extracting the heat from cavity and productivity are not achieved, it might be necessary to redesign the part geometry to fit mould limitations. An alternative to solve complex thermal issues is the use of copper-beryllium $(\mathrm{Cu}-\mathrm{Be})$ inserts [1]. As $\mathrm{Cu}-\mathrm{Be}$ inserts have higher thermal conductivity than the usual steel alloys, they are used to extract heat from regions where the cooling channels do not have an effect during the injection moulding cycles. Nevertheless, they are not environmentally friendly, as beryllium is cited as a highly carcinogenic element [2]. Another limitation is that inserts in the mould impression might leave marks in the part as the mould surface has a visible interface between the base material and the insert. In addition, the insert features that are needed to attach it to the base contribute to reducing the space left for the cooling channels.

In the mid 1980s, new manufacturing technologies known as SFF (solid free-form fabrication) emerged [3]. The main difference of these technologies, as opposed to the traditional ones, was that they were based on the layer additive principle. Also known as rapid prototyping (RP), these technologies can produce parts in low-volume production in virtually any form or material. The variety of available materials is limited; however, RP processes can build parts in metals, ceramics, and polymers [3]. RP technologies are highly automated and they are also called threedimensional (3D) printers as the machines almost 'print' solid parts from data generated from computer software. Designers and engineers can build and verify designed parts without misunderstandings, inaccuracies, and delays. The basic principle of RP technologies is to build, layer-by-layer, material corresponding to the data of the designed part. Raw materials can be liquid resins, wires, pastes, powders, and sheets. The way to shape these materials and bond layers can be diverse including ultraviolet lasers, lamps, power lasers, spray of glue, deposition of fused material, and others. These additive-layered manufacturing technologies (LMTs) have also been used to produce tools for injection moulding. Depending on the technology and material used in construction, the complexity of the mould impression (injected part), and the injected material, these moulds can be competitive to traditional cast $/$ milled moulds. It is possible to build moulds from 12 to 10000 parts according to the technology, material, and application $[\mathbf{4}, \mathbf{5}]$. One interesting technique used with SFF to build injection moulds is conformal cooling channels. The channels are designed in the mould impression without the concerns of the limitations from the traditional manufacturing method. The conformal cooling channels might follow the mould impression surface, passing by the ejector system with fewer limitations than the usual moulds. Unfortunately, they are still limited by the ejection system and some part features such as deep groves might not be affected by the cooling capabilities of the channels. To overcome some of these constraints, it is possible to use functionally graded materials (FGMs) to build injection moulds by SFF technologies.

FGMs have been the subject of research for the last 25 years [6]. Most of the natural materials such as minerals and tissues have a gradual change from one functional region to another. This example of nature inspires integrated form and function design all in the same component/unit. FGM is not completely new to the manufacturing processes, but it was only after the 1980s that it started to receive more attention and to be classified as a specific research subject. The basic idea of FGM is to improve the properties of the part by varying the quantity of an 'ingredient' in specific regions in order to achieve differential properties. An ingredient could be a basic element such as carbon being used to increase the hardness of a steel part only at the surface. Another example is the porosity variation from the outside to the inside of the mammal's bones. The low porosity from the outside increases the stiffness of the bone but provides interconnectivity to the inside. The core of the bone is porous, thereby allowing weight efficiency. By using this variation from one material to another, optimized components can be obtained. Reduced number of joints and fasteners, weight reduction, structural enhancement, differential heat extraction, thermal barriers, embedded sensors, and biocompatible implants are some of the potential advantages of using FGM [6-8]. FGMs also could gradually join dissimilar materials with different properties in the same component. The principle is similar to composite materials. The difference is that composites have distinctive phases and do not vary their composition in the volume of the component. Despite the idea of FGMs being very simple, most of the potential FGM applications are restricted to technological limitations and high cost. Difficulties in controlling and depositing the gradient composition and producing complex shapes with computer-aided design (CAD), computer-aided manufacturing (CAM), and finite element analysis (FEA) integration are some of the causes for restrictions of use.

The use of RP technologies to produce FGM parts has been investigated by many researchers [9]. Since $\mathrm{RP}$ technologies can produce free-form parts and can handle different materials, it is possible to use them 
to produce FGM components. Most of the researchers investigating the fabrication of FGM by LMTs process the materials with the heat source delivered by a laser beam. As lasers can be easily automated and can deliver high-energy densities with precision and speed, they can process almost any material [10]. Another aspect of FGM and RP is the frequent use of materials in the form of powder to be fused or pre-sintered under a laser spot. The main issue for using rapid processing and manufacturing technologies for producing FGM parts is the local composition control (LCC). This regards the principle for adding and joining the materials by controlling their percentages on each region of the part or layers. Some researchers $[\mathbf{1 1}, 12]$ used miniature hopper-nozzles and capillary tubes to control the deposition of powders in the layer. Ensz et al. [13] studied the optimization of two powder flows in the laser engineering netshaping (LENS ${ }^{\mathrm{TM}}$ ) process to build gradients from H13 to M300 steel alloys. In addition, computational methods to represent the graded geometry have been the subject of study. Cho et al. [14] investigated the LLC for the 3D printing process after obtaining geometry and material data from finite element and voxel space geometries. By this method, it was possible digitally to represent the $3 \mathrm{D}$ part with different volumetric gradients.

The idea of adding an extra functional material to a base material to produce a FGM injection mould has been researched in previous work [15]. A multicompartment hopper was used to produce graded structures of $\mathrm{H} 13$ tool steel and $\mathrm{Cu}$. The $\mathrm{H} 13$ is commonly used as material for injection moulds as it has dimensional stability, toughness, and wear resistance at high temperature. Nevertheless the heat conduction of this material is low compared with $\mathrm{Cu}\left(k_{\mathrm{H} 13}: 24.3 \mathrm{~W} / \mathrm{m} \mathrm{K} ; k_{\mathrm{Cu}}\right.$ : $\left.385 \mathrm{~W} / \mathrm{m} \mathrm{K}[\mathbf{1 6}, \mathbf{1 7}]\right)$. Elemental $\mathrm{Cu}$ powder was mixed with $\mathrm{H} 13$ in proportions of $12.5,25,37.5$, and $50 \%$ wt to produce FGM bars. The method for producing these bars was the selective laser fusion/melting (SLF or SLM) using a high-powder Nd:YAG pulsed laser. The laser processed the multi-composition powder bed that was previously loaded with powders from the multicompartment hopper. As the laser scanned the powder bed, the powder was fused and bonded to the previous added layers. After processing a layer, the powder bed was lowered and the powders were spread over the previous layer and the laser was set to fuse the powder to form a new layer. This process was numerically controlled and continued until the completion of the part. The fusion process, using this laser, left a rough superficial aspect and required some post processing including the removal of the substrate that was used to bond the first layers of the part to the powder bed platform. At the end of the process, graded parts of $\mathrm{H} 13$ and $\mathrm{Cu}$ could be obtained. Therefore, FGMs could be used on injection moulds to create high heat conductivity regions to improve heat extraction. As the cooling/heating channels can be limited by manufacturability and the ejector system, some regions of the impression could be over heated. This differential heat extraction from the part might cause warpage, sink and cold welding marks, and poor surface quality, and could reduce the production rate of the part. Another application of FGM on moulds is to build the cavity edges with gradients of tool steel and tungsten carbide. This could improve the part quality by reducing defects such as flashing caused by wear in the mould edges [1].

The use of FGM to obtain performance injection moulds was one of the stimuli for this research. Despite the limitations of the laser and layer deposition systems used in this work, these experiments were planned to evaluate the influence of the $\mathrm{Cu}$ addition to the $\mathrm{H} 13$ matrix. The effect of the addition of $\mathrm{Cu}$ on the mould temperature and on the injected polymer part crystallinity degree, compared with the H13 base material, was analysed. In theory, the addition of $\mathrm{Cu}$ would increase the thermal conductivity of the mould. The work was divided in two parts: numerical modelling of the heat transfer and experimental injection moulding. The first part presents the numerical model of the heat transfer from the injected part to the mould and the metallic inserts. The model evaluated the temperature time stamp, simulating mould inserts in different materials: $\mathrm{H} 13, \mathrm{Cu}$, and $\mathrm{H} 13+50 \% \mathrm{Cu}$. In the injection moulding experiment, FGM bars (mould inserts) were manufactured by laser fusion and placed in a stereolithography (SL) mould. Polypropylene (PP) parts were produced by injecting the polymer over these metallic inserts. Two outputs were analysed from this experiment: temperature of the mould surface and crystallinity degree of the PP parts. The temperature of the mould was measured by thermocouples in the exact same position taken in the numerical model. The degree of crystallinity of the parts, moulded with different inserts, was analysed by differential scanning calorimetry (DSC). The DSC test was performed to identify if the parts moulded over different inserts had different cooling rates. As a consequence, the degree of crystallinity of the parts could be different too. The lower the cooling rate, the greater is the organization of the polymer chains reflecting in the crystallinity degree of the PP. A rapid cooling rate helps the polymer to hold an amorphous structure. When heating a plastic, more heat will be necessary to dissolve the crystals (more stable and lower energy state) until the plastic is completely melted. This phenomenon can be seen in the DSC curves measuring the energy absorbed by the sample before melting [18]. 


\section{METHODOLOGY}

\subsection{Numerical model}

The injection moulding cycle is a transient phenomena and thermal conductivity is not the only material property that counts when analysing the heat transfer. Density and specific heat capacity also determine the capability of the material to store or to transport energy [19]. Considering volume control, the energy state is obtained by the balance of the energy that is absorbed, generated, and lost. This variation of the energy accumulated by the mass inside the volume can be modelled by equation (1). The energy that enters $\left(\dot{E}_{\text {in }}\right)$ plus the energy generated $\left(\dot{E}_{\text {gen }}\right)$ inside the volume minus the energy lost $\left(\dot{E}_{\text {out }}\right)$ to the surroundings is equal to the variation of energy $(E)$ of the mass inside the volume with respect to time $(t)$.

$$
\dot{E}_{\text {in }}-\dot{E}_{\text {out }}+\dot{E}_{\text {gen }}=\left.\frac{\mathrm{d} E}{\mathrm{~d} t}\right|_{\nu c}
$$

In the case of a mould, in the moments after the melted material fills the mould impression, there is no heat generated in defined volume control. Considering the heat transfer in one direction, equation (1) becomes further simplified for the heat flux through an area $A$, generating equation (2). Simplifying the area, equation (3) is generated. In these equations, $q^{\prime \prime}$ represents the heat fluxes, $\rho$ is the material density, $c_{\mathrm{p}}$ symbolizes the specific heat, $T$ is the temperature, and $x$ is the axis of the direction of the heat flux.

$$
\begin{aligned}
& q_{\text {in }}^{\prime \prime} A-q_{\text {out }}^{\prime \prime} A+0=\int_{x} \rho c_{\mathrm{p}} \frac{\partial T}{\partial t} A \mathrm{~d} x \\
& q_{\text {in }}^{\prime \prime}-q_{\text {out }}^{\prime \prime}=\int_{x} \rho c_{\mathrm{p}} \frac{\partial T}{\partial t} \mathrm{~d} x
\end{aligned}
$$

The temperature in the mould, away from the impression, could be considered constant. Taking this into consideration, in a very short period the heat fluxes can be considered constant and can be described as in equation (4), where $k$ is the heat conduction coefficient.

$$
q^{\prime \prime}=\left.k \frac{\partial T}{\partial x}\right|_{x}
$$

There is no easy solution for solving equations (3) and (4) and a numerical model is usually necessary to solve them for complex shapes. A two-dimensional (2D) model of an injection moulded part inside a SL mould in contact with a metallic insert is shown in Fig. 1. This model considered no contact resistance between the parts, moulds, and insert surfaces. The initial conditions were that the temperature in the nodes inside the area that represents the hot PP injected part was $195^{\circ} \mathrm{C}$ and the temperature for all other nodes, including the connected nodes of the

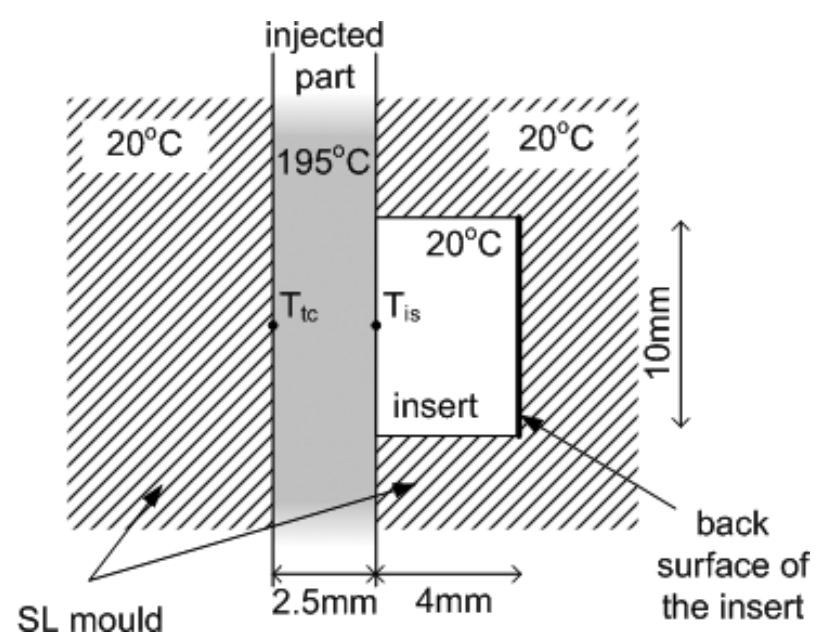

Fig. $12 \mathrm{D}$ model for the heat transfer of an injected part in contact with a metallic insert in a SL mould (initial temperature indicated for each area of the model)

part with other areas, was $20^{\circ} \mathrm{C}$. Temperature was calculated by employing a quadrangular mesh formed by planar four-node elements. The nodes chosen to be analysed are indicated in Fig. 1. Thermocouple temperature, $T_{\mathrm{tc}}$, matched the same position in the experimental work and insert surface temperature, $T_{\text {is }}$, matched the region from where DSC samples were taken in the PP part. The model and analysis were performed using Ansys software.

For inputting the material properties (density, specific heat, and thermal conductivity) in the numerical model, tabled values were used for the H13 [16]. However, the $\mathrm{H} 13+50$ per cent material properties values were estimated based on the Voight and Reuss rules of mixtures $[\mathbf{5}, \mathbf{6}]$. The basic rule of mixtures (Voight) is presented in equation (5). An equivalent property $(\varepsilon)$ of the mixture formed by $\alpha$ and $\beta$ phases is calculated by the summation of the property of each phase and the volume fraction $(V)$ of the phases in the mixture, resulting in a linear variation between each phase value property. The second rule expressed in equation (6) is more elaborate, but neither rule counts the phase interaction, phase geometry, space distribution, and other factors that affect the final property of the mixture. Nevertheless, the second rule is more conservative than the first one. The material properties used in the numerical model are presented in Table 1.

$$
\begin{aligned}
& \varepsilon_{\text {Voight }}=V_{\alpha} \varepsilon_{\alpha}+V_{\beta} \varepsilon_{\beta} \\
& \varepsilon_{\text {Reuss }}=\frac{\varepsilon_{\beta} \varepsilon_{\alpha}}{V_{\alpha} \varepsilon_{\beta}+V_{\beta} \varepsilon_{\alpha}}
\end{aligned}
$$

In total, six simulations of the time versus temperature in the nodes $T_{\mathrm{tc}}$ and $T_{\text {is }}$ (refer to Fig. 1) were made using different insert materials specified in Table 1. The first four simulations were performed 
with all node temperature being time dependent. The other two simulations were calculated considering that the nodes in the back surface of the insert were kept at a constant temperature of $20^{\circ} \mathrm{C}$, without changes with respect to time. This was made to simulate the case of using a cooling channel in the back of the insert. The numerical simulations are listed in Table 2.

\subsection{Injection moulding experiment}

To investigate the effect that FGM had on injection moulded parts, graded inserts of $\mathrm{H} 13$ and $\mathrm{Cu}$ were manufactured using SLM and a multi compartment hopper. The laser scanned tracks over a graded powder bed. This graded powder bed was spread by the hopper with different blends of powders. The laser energy melted the powder building a graded structure layer-by-layer. A basic sketch of the process is shown in Fig. 2.

To produce the inserts, bimodal-sized mixtures of $\mathrm{H} 13$ and $\mathrm{Cu}$ powders were used. The powders with $\mathrm{H} 13+12.5 \% \mathrm{Cu}, \mathrm{H} 13+25 \% \mathrm{Cu}, \mathrm{H} 13+37.5 \% \mathrm{Cu}$, and $\mathrm{H} 13+50 \% \mathrm{Cu}$ (weight fractions) and pure $\mathrm{H} 13$ powder were placed on ceramic ball mills for proper mixing of the powders. The average ratio between the diameter of large and fine particles of powders was $6.6: 1$. This is close to $7: 1$, which is suggested in the literature for increasing the apparent density (packing) of powder consisting of spherical particles [22]. The large particles of $\mathrm{Cu}$ and $\mathrm{H} 13$

Table 1 Material properties used in the numerical model

\begin{tabular}{|c|c|c|c|c|}
\hline Model area & Material & $\begin{array}{l}\text { Density } \\
\left(\mathrm{g} / \mathrm{cm}^{3}\right)\end{array}$ & $\begin{array}{l}\text { Heat } \\
\text { capacity } \\
\left(\mathrm{J} / \mathrm{g} .{ }^{\circ} \mathrm{C}\right)\end{array}$ & $\begin{array}{l}\text { Heat } \\
\text { conduction } \\
(\mathrm{W} / \mathrm{m} \mathrm{K}) \\
\end{array}$ \\
\hline SL mould & $\begin{array}{l}\text { RenShape } 7580 \\
\text { resin }[\mathbf{2 0}]\end{array}$ & 1.22 & $2.00^{*}$ & $0.2^{*}$ \\
\hline Part & Polypropylene [21] & $1.00^{\dagger}$ & 2.00 & 0.13 \\
\hline \multirow[t]{4}{*}{ Insert } & $\mathrm{H} 13[\mathbf{1 6}]$ & 7.80 & 0.460 & 24.3 \\
\hline & $\mathrm{Cu}[\mathbf{1 7}]$ & 8.96 & 0.385 & 385.0 \\
\hline & $\mathrm{H} 13+50 \% \mathrm{Cu}-$ Voight & 8.34 & 0.425 & 192.2 \\
\hline & $\mathrm{H} 13+50 \% \mathrm{Cu}-$ Reuss & 8.30 & 0.422 & 43.1 \\
\hline
\end{tabular}

*estimated

†average were within the range $105-150 \mu \mathrm{m}$. The small particles of $\mathrm{Cu}$ were less than $22 \mu \mathrm{m}$ in diameter size and the H13 particles less than $38 \mu \mathrm{m}$. The AISI H13 tool steel alloy (BS EN ISO 4957:2000 XV40CrMoV5-1) composition was, in percentage weight: Fe 90.8\%, C 0.32$0.42 \%$, Cr 4.75-5.25\%, Mn max. 0.4\%, Mo 1.25-1.75\%, Si $0.85-1.15 \%$, and V $0.9-1.1 \%$ and the copper powder was $99.99 \% \mathrm{Cu}$ oxygen free (OHFC) [23].

The different compositions of powder were used to fill the multi-compartment hopper and spread over a mild steel substrate. The computer numerically control (CNC)-laser-guided system melted the powder, layer-by-layer, using a specific scan strategy pattern developed for this technique and described in detail in reference [15]. This strategy was divided in to two stages. In the first step, the laser was set to fuse spaced lines of powder leaving a gap between the lines. A refill of powder between these solidified lines was executed with the hopper sliding the powder bed (without moving the platform). In the second step of the scanning strategy, the laser was set to melt the new powder deposited in the gaps. The laser processing parameters were: energy pulse $10 \mathrm{~J}$, pulse width $20 \mathrm{~ms}$, repetition rate $2 \mathrm{~Hz}$, and scan speed

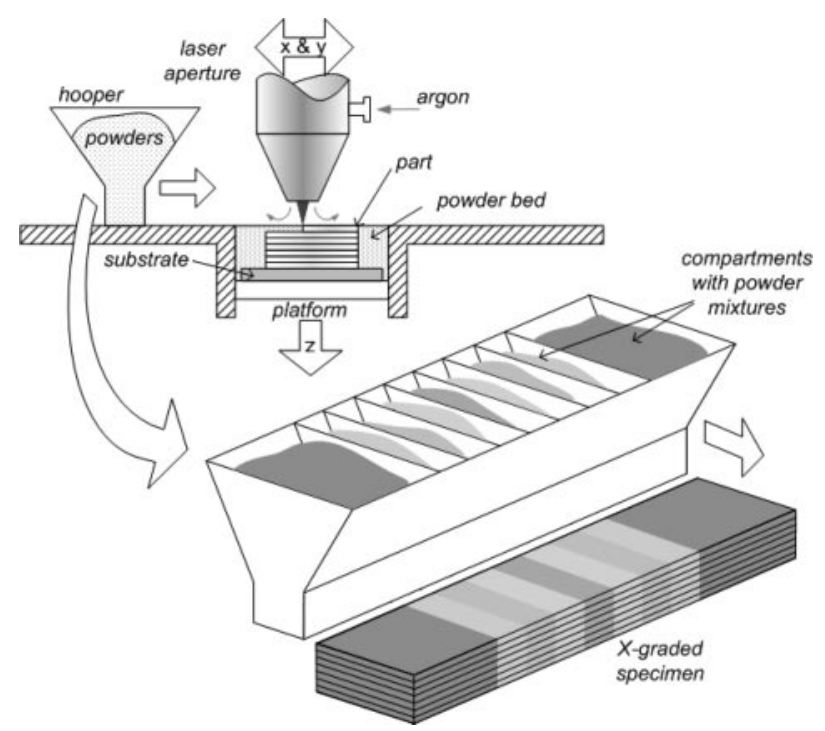

Fig. 2 The selective laser fusion process and the multicompartment hopper for spreading $\mathrm{x}$-graded powder bed

Table 2 Conditions of the numerical simulations

\begin{tabular}{|c|c|c|c|}
\hline $\begin{array}{l}\text { Condition of } \\
\text { the insert }\end{array}$ & $\begin{array}{l}\text { Initial temperature } \\
\text { of the injected part }\end{array}$ & $\begin{array}{l}\text { Initial temperature of } \\
\text { the moulds and inserts }\end{array}$ & $\begin{array}{l}\text { Temperature at the } \\
\text { back surface of the insert }\end{array}$ \\
\hline $\begin{array}{l}\mathrm{H} 13 \\
\mathrm{Cu} \\
\text { H13-50Cu Voight } \\
\text { H13-50Cu Reuss }\end{array}$ & $195^{\circ} \mathrm{C}$ & $20^{\circ} \mathrm{C}$ & Initial $20^{\circ} \mathrm{C}$ \\
\hline $\mathrm{H} 13$ & $195^{\circ} \mathrm{C}$ & $20^{\circ} \mathrm{C}$ & $\begin{array}{l}\text { Constant } 20^{\circ} \mathrm{C} \\
\quad \text { (cooling system) }\end{array}$ \\
\hline
\end{tabular}




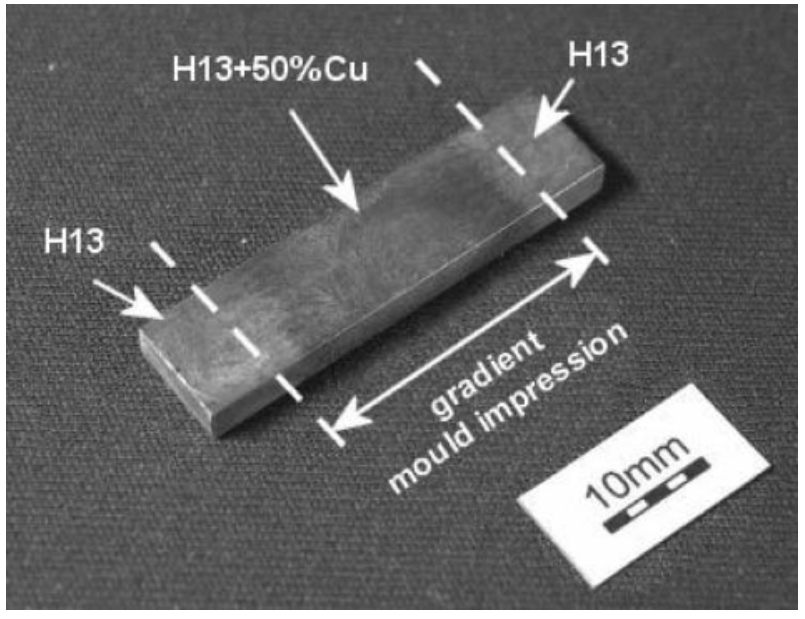

Fig. 3 FGM insert and the disposition of the gradients

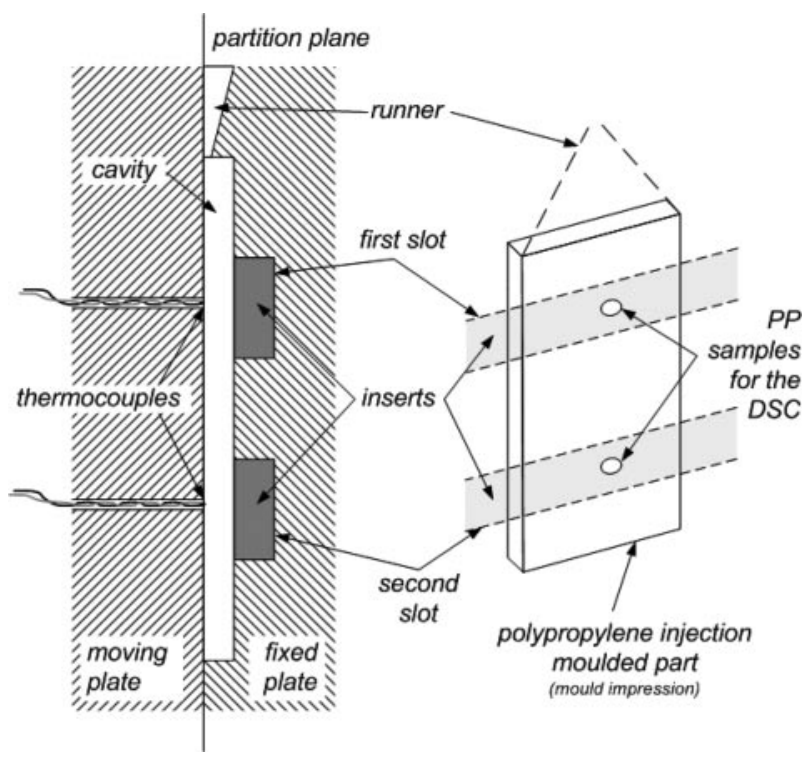

Fig. 4 Position of the thermocouples in the cavity

$5 \mathrm{~mm} / \mathrm{s}$. The layer thickness used was $250 \mu \mathrm{m}$ and argon (Ar) was used to reduce oxidation. After building the specimens, they were post processed by cutting off the substrate and grinding its surfaces. The final dimensions of the graded insert and the distribution of the gradient are presented in Fig. 3. Each different mixture of $\mathrm{Cu}$ and $\mathrm{H} 13$ was $3.5 \mathrm{~mm}$ wide. A pure $\mathrm{H} 13$ insert was made from stock annealed H13 by cutting and grinding and had the same dimensions as the FGM specimen.

An injection mould was designed specifically to hold and swap the inserts. The design of the impression consisted of a simple slab $30 \times 60 \times 2.5 \mathrm{~mm}$ (Fig. 4). The SL process was used to build the mould. This choice was taken because SL resins have low thermal conductivity and can work as an insulator. Therefore, the influence of the metallic inserts would be more distinctive. The mould design considered
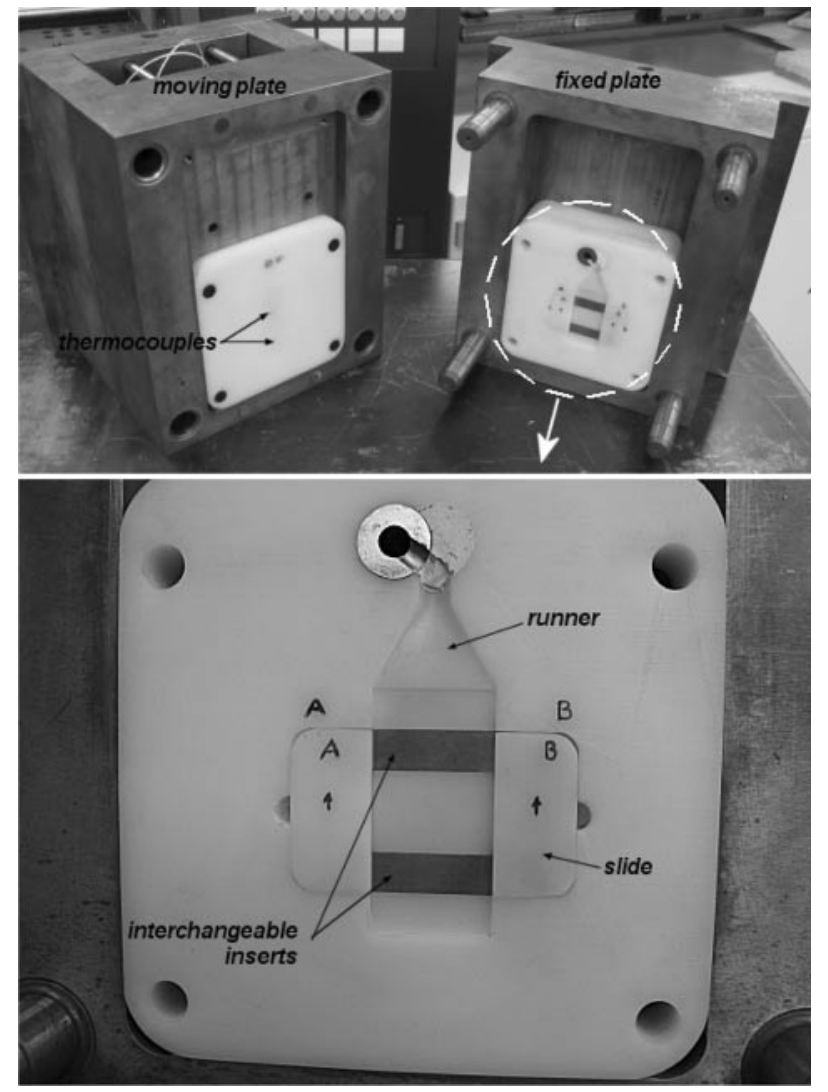

Fig. 5 Injection mould (above) and the interchangeable inserts in detail (below)

also the placement in the mould of two thermocouples to read the mould surface temperature during the injection cycles. The positions of the thermocouples are shown in Fig. 4.

The mould was built using a 3D Systems SLA7000 stereolithography machine in Huntsman RenShape 7580 resin. The K-type thermocouples were positioned and glued to the mould's surface using a commercial epoxy bi-compound resin (Araldite). After the epoxy glue hardened, it was sanded until the thermocouple tips were exposed. Figure 5 shows in detail the mould finished and assembled in the bolsters ready to be mounted in the injection moulding machine. The injection moulding machine used was a Battenfeld TM750/210 and thermocouples were connected to a CR10X data logger from Campbell Scientific. Data were collected each $5 \mathrm{~s}$ and the room temperature was $20^{\circ} \mathrm{C}$. The injection moulding material was the Solvay Eltex-P HY202 PP.

The injection moulding procedure started by placing the FGM insert in the first slot and the H13 in the second slot. After 20 injection cycles, the inserts were swapped and the FGM insert was placed in the second slot, the H13 in the first slot, and a further 20 cycles were performed. Table 3 shows the injection moulding cycle and the insert position on each slot corresponding to Fig. 4. 
Table 3 Injection moulding order and position of the inserts

\begin{tabular}{lll}
\hline & First slot & Second slot \\
\hline Injection moulding A series (IMA) & FGM insert & H13 insert \\
Injection moulding B series (IMB) & H13 insert & FGM insert \\
\hline
\end{tabular}

Table 4 Injection moulding parameters

\begin{tabular}{ll}
\hline Parameter & Setting \\
\hline Clamping force & $64 \mathrm{kN}$ \\
Injection pressure & $160 \mathrm{bar}$ \\
Injection speed & $10 \mathrm{ccm} / \mathrm{s}$ \\
Injection temperature & $195{ }^{\circ} \mathrm{C}$ (nozzle) \\
Holding pressure & $60 \mathrm{bar}$ (during $1 \mathrm{~s})$ \\
Cooling time & $30 \mathrm{~s}$ \\
Time before next injection (open mould) & $120 \mathrm{~s}$ \\
\hline
\end{tabular}

Between each mould opening, a delay of $120 \mathrm{~s}$ was taken to allow the inserts to cool down. A release agent was not necessary as the geometry was simple and an ejection draft angle was used in the mould impression surfaces to make part ejection easier $\left(1.5^{\circ}\right)$. The injection moulding parameters were kept constant and they are presented in Table 4 . The low injection and holding pressures are typically used in SL moulds. Most of the SL resins became soft above $80^{\circ} \mathrm{C}$ and high pressures and temperatures had to be avoided in order to increase the mould's life.

Samples from PP parts obtained in the second and sixteenth cycles of the A and B injection moulding series were taken from the DSC test. The apparatus used for these tests was a Shimadzu DSC-60. The samples were taken from the same position for all parts and matched the face in contact with the inserts (FGM and H13) on the same region where the thermocouples were placed. Figure 4 indicates these regions from sampling. The PP samples, having masses between 5 and $7 \mathrm{mg}$, were inserted on aluminium pans for DSC, covered, and placed in the apparatus. The tests were performed from room temperature (19$21^{\circ} \mathrm{C}$ ) to $300^{\circ} \mathrm{C}$ with a heating rate of $10^{\circ} \mathrm{C} / \mathrm{min}$. The results were analysed using the Shimadzu ta60 version 1.51 analysis software. As explained earlier, the main objective of the DSC tests was to compare the degree of crystallinity of a part obtained using different inserts in the injection moulding impression. The percentage of crystallinity can be calculated by equation (7). $\Delta H$ is the heat of fusion for the polymer tested and the $\Delta \mathrm{H}_{100 \%}$ is the heat of fusion for the same polymer with 100 per cent crystallinity [24].

$$
\chi \%=\frac{\Delta H}{\Delta H_{100 \%}}
$$

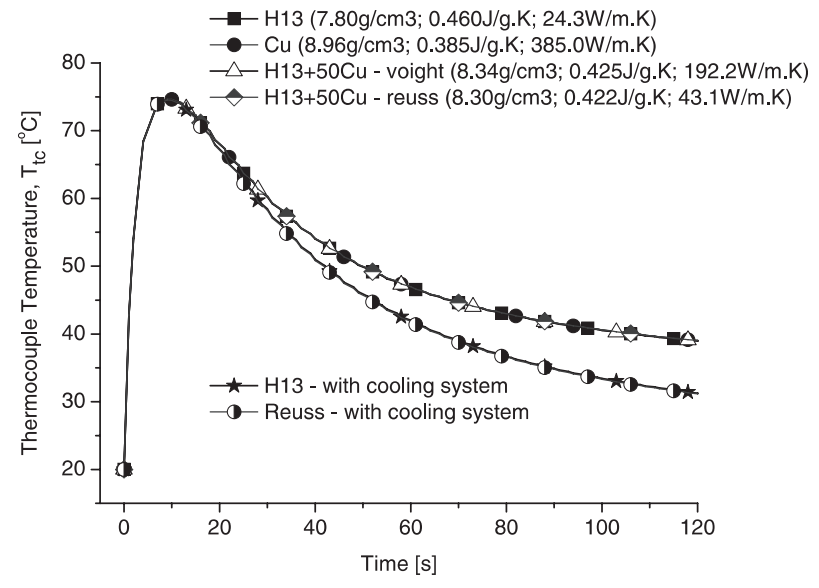

Fig. 6 Estimated temperature of the thermocouple $\left(T_{\mathrm{tc}}\right.$, mould surface) plotted against the time simulating different material properties for the insert

\section{RESULTS}

\subsection{Numerical analysis results}

From the numerical simulations it was possible to plot the temperature against the time for the areas (nodes) that represented the thermocouples and surface of the inserts. The calculated temperature in the node that represents a thermocouple $\left(T_{\mathrm{tc}}\right)$ is shown in Fig. 6. For the simulations without cooling system (H13; Cu; H13+50Cu - Voight; $\mathrm{H} 13+50 \mathrm{Cu}$ - Reuss) the curves of Fig. 6 showed that there was no difference between the cooling rate, although the material of the insert was different. For the simulations with the cooling channel (temperature of the back surface of the insert constant at $20^{\circ} \mathrm{C}$ ), it showed that the curves for the two tested insert materials ( $\mathrm{H} 13$ and $\mathrm{H} 13+50 \mathrm{Cu})$ had a more accelerated cooling effect compared with the inserts without cooling. Nevertheless, it showed no difference in the cooling rate between them.

The results from the other node that represented the insert surface temperature were relevantly different. Figure 7 shows the temperature plotted against time for node $T_{\text {is. }}$. The heating and cooling rates of the insert surface without simulation of the cooling system showed that there were no significant changes in the cooling rate although the materials' properties were different. For the other two analyses that simulated the cooling system in the back surface of the insert, the results showed that the material affected the cooling rate. In Fig. 7 the curves of $\mathrm{H} 13$ and $\mathrm{H} 13+50 \mathrm{Cu}$, estimated by the Reuss equation, had higher cooling rates than the other simulated conditions and it demonstrated that the insert simulating the FGM $(\mathrm{H} 13+50 \mathrm{Cu}$ - Reuss) would have a faster cooling rate than the insert of pure H13. 


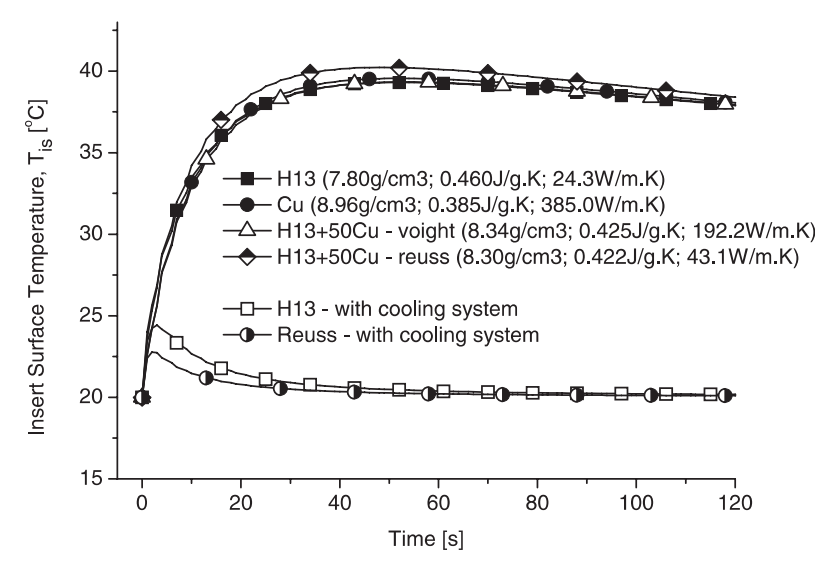

Fig. 7 Temperature of the insert surface $\left(T_{\text {is }}\right)$ plotted against the time simulating different material properties for the insert

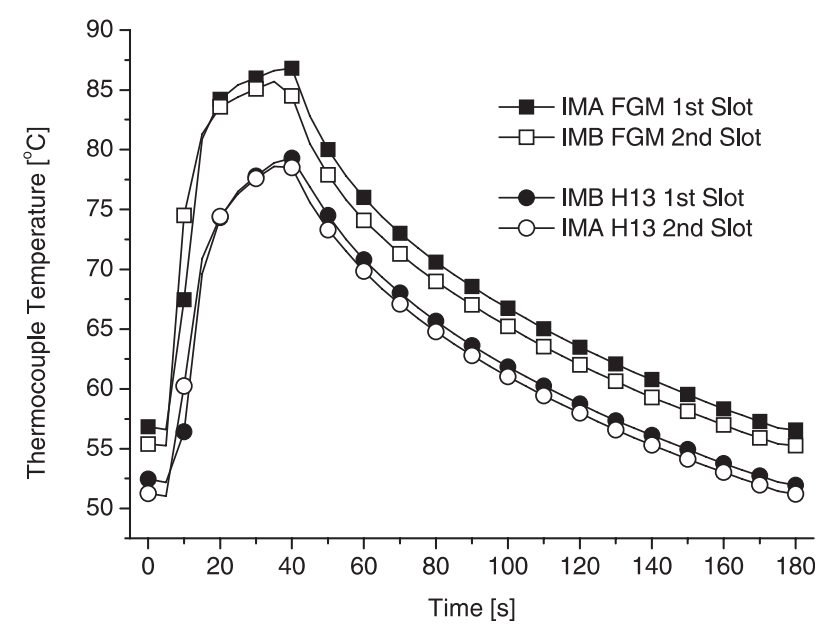

Fig. 8 Temperature of the mould surface, $T_{\mathrm{tc}}$, during the injection moulding

\subsection{Injection moulding experiment results}

The temperatures measured from the thermocouples during typical injection moulding cycles are plotted in Fig. 8. This figure shows that the temperature for the FGM inserts was higher than the temperature for inserts made of only H13. This behaviour was independent from the order of the slot as shown in Fig. 8. Also, the temperature of the mould surface for the position of the FGM insert was considerably higher than the H13 insert. In addition, the temperature for $\mathrm{H} 13$ inserts was similar to the numerical model. On the other hand, the FGM temperature was considerably higher than the numerical results obtained.

The DSC results reflected the behaviour of the temperature measured with the thermocouples. The FGM insert presented higher temperature and lower capacity to absorb the heat from the part. This was identifiable by the higher energy necessary to dissolve the more crystalline samples moulded over

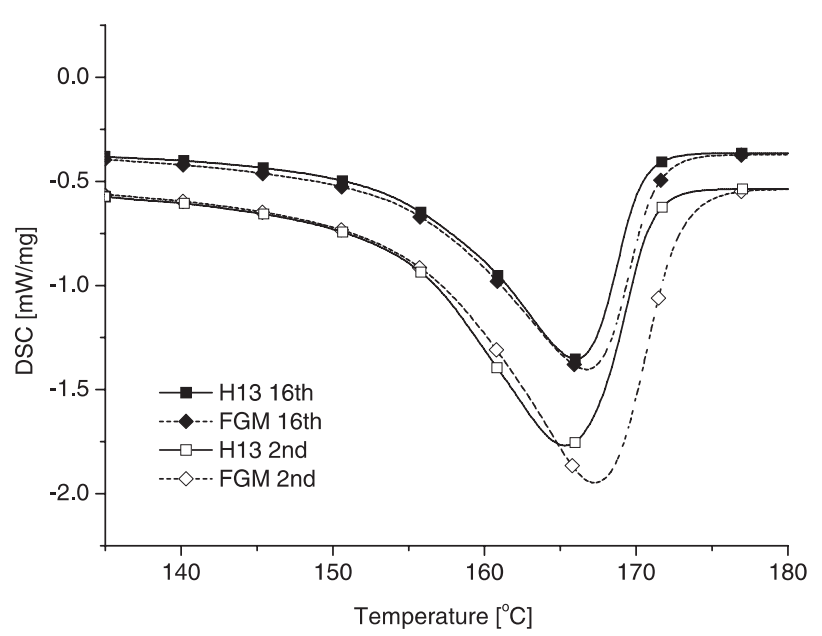

Fig. 9 Calorimetric plot of the samples taken from PP parts of the second injection moulding cycles over the first slot (H13 2nd and FGM 2nd) and over the second slot in the 16th cycles (H13 16th and FGM 16th)

Table 5 DSC summary of the PP samples analysed

\begin{tabular}{|c|c|c|c|c|c|c|}
\hline Slot & $\begin{array}{l}\text { Injection } \\
\text { moulding } \\
\text { series }\end{array}$ & Insert & $\begin{array}{l}\text { Peak } \\
\text { temperature } \\
\left({ }^{\circ} \mathrm{C}\right)\end{array}$ & $\begin{array}{l}\text { Heat } \\
(\mathrm{m})\end{array}$ & $\begin{array}{l}\text { Heat/ } \\
\text { mass } \\
(\mathrm{J} / \mathrm{g})\end{array}$ & $\begin{array}{l}\text { Crystallinity } \\
\text { degree } \\
(\%)\end{array}$ \\
\hline \multirow[t]{2}{*}{$1 \mathrm{st}$} & IMA & FGM & 167.22 & 635.10 & 109.50 & 52.4 \\
\hline & IMB & H13 & 165.28 & 548.09 & 94.50 & 45.2 \\
\hline \multirow[t]{2}{*}{ 2nd } & IMB & FGM & 166.69 & 464.57 & 76.16 & 36.4 \\
\hline & IMA & H13 & 165.99 & 382.85 & 63.81 & 30.5 \\
\hline
\end{tabular}

the FGM insert. The curves of the DSC shown in Fig. 9 also reveal that with a hotter mould, sixteenth cycle, a higher crystallinity could be observed in the samples. Table 5 shows the difference between the energy per gram that was necessary to melt the samples. Also, the percentage crystallinity is calculated based on equation (7). The reference for 100 per cent crystalline polypropylene was $209 \mathrm{~J} / \mathrm{g}$ [25].

\section{DISCUSSION AND CONCLUSIONS}

The measured temperature of the mould surface showed different results from those obtained from the numerical experiments. The temperatures in the mould surface were higher than the simulated results. In addition, analysis of the curves' dropdown showed that the cooling rate of the simulation was higher than the real readings. The difference might be from different causes. The model did not consider phase and property changes of the polymer during its solidification. Additionally, the fittings of the inserts in the rough SL bolster do not provide a perfect contact surface, as considered in the numerical model. Another source affecting the results was that the computational model was based on estimations of 
properties of the graded material. The FGM material has its porosity and internal cracks from the build process. The rules of mixtures did not consider these voids in the material. The stock H13 insert presented less difference between the injection moulding and numerical results as it did not present these voids inside its microstructure. Confirming this theory, the comparison between the results showed that the behaviour of the cooling curves was equivalent, but there was a small distinction between the $\mathrm{H} 13$ and FGM curves in the results from the numerical model. For the real data measurements, it was possible to identify that the $\mathrm{H} 13$ was more efficient than the FGM inserts in absorbing and storing the heat. The difference between the inserts' performance showed a temperature peak around 7 degrees lower for the $\mathrm{H} 13$ insert. As the objective of the addition of $\mathrm{Cu}$ to the $\mathrm{H} 13$ was to increase conductivity it was necessary to simulate a condition to compare the heat being transferred through the inserts. Consequently, the numerical results simulating the cooling channels in the back surface of the inserts showed that the $50 \% \mathrm{Cu}-\mathrm{H} 13$ insert had better capacity to transport the heat away from the part than the pure H13 insert.

The DSC results showed no surprise as the temperature studies in the numerical and practical experiments had shown that the FGM mould was absorbing the heat slower than the pure $\mathrm{H} 13$ insert. Although the properties of the $50 \% \mathrm{Cu}-\mathrm{H} 13$ mixture were unknown, it is reasonable to say that these properties are lower than the expectation comparing the thermal performance of pure $\mathrm{Cu}$. Some of the factors that might be affecting the results have already been identified in previous work [15]. Porosity and cracks in the microstructure of the different proportions of $\mathrm{Cu}$ and $\mathrm{H} 13$ affected the thermal properties. Optimization in the building process can reduce these voids and increase material properties.

Although the results that the conductivity of the $\mathrm{Cu}-\mathrm{H} 13$ mixtures was lower than expected, it showed that it could be used for achieving different cooling rates in the mould using cooling channels. The combination of FGM with conformal cooling can bring clear benefits to improve heat extraction, especially in cases of deep grooves, thin walls, and highly complex parts. Higher proportions of $\mathrm{Cu}$ in the gradient might increase the thermal heat transfer capabilities of these regions. Even so, care must be taken as the mechanical properties are not characterized and it would be expected that the material would be softer and less tough.

\section{ACKNOWLEDGEMENTS}

The authors would like to thanks to Capes and CNPq (Ministries of Education and Science and
Technology, Brazil) for funding support. Also a special thanks to Juliano Heidrich, Naguib Saleh, Bob Temple, and Rod Springthorpe.

\section{REFERENCES}

1 Menges, G. and Mohren, P. How to make injection molds, 2nd edition, 1993 (Hanser, Munich).

2 Center for Epidemiologic Research. Former beryllium workers medical surveillance program. Oak Ridge Institute for Science and Education, Oak Ridge, Tennessee, USA, available online at http://www.orau.gov/cer/ BMSP_pro/be-home.htm (accessed December 2005).

3 Jacobs, P. F. Stereolithography and other RP\&M technologies, 1996 (RPA/ASME Press, New York).

4 Ahrens, C. H., Ribeiro, A. S., and Beal, V. E. An alternative cooling technique for stereolithography moulds. Proceedings of Time-compression technologies 2001 Conference, Manchester, UK, 26-27 September 2001.

5 Dalgarno, K. and Stewart, T. Production tooling for polymer moulding using the RapidSteel process. Rapid Prototyping J., 2001, 7(3), 173-179.

6 Miyamoto, Y., Kaysser, W. A., Rabin, B. H., Kawasaki, A., and Ford, R. G. Functionally graded materials: design processing and applications, 1999 (Kluwer Academic Publishers, Dordrecht, The Netherlands).

7 Suresh, S. and Mortensen, A. Fundamentals of functionally graded materials, 1998 (Institute of Materials, London).

8 Calder, N. Rapid manufacturing of functional materials. Proceedings of Time-compression technologies 2001 Conference, Manchester, UK, 26-27 September 2001.

9 Shishkovsky, I. Synthesis of functionally gradient via RP methods. Rapid Prototyping J., 2001, 7(4), 207-211.

10 Steen, W. M. Laser material processing, 1991 (SpringerVerlag, New York).

11 Kumar, P., Santosa, J. K., Beck, E., and Das, S. Directwrite deposition of fine powders through miniature hopper-nozzles for multi-material solid freeform fabrication. Rapid Prototyping J., 2004, 10(1), 14-23.

12 Yang, S. and Evans, J. R. G. Acoustic control of powder dispensing in open tubes. Powder Technol., 2004, 139(6), 55-60.

13 Ensz, M. T., Griffith, M. L., and Reckaway, D. E. Critical issues for functionally graded material deposition by laser engineered net shaping (LENS TM). Proceedings of the 2002 International Conference on Metal powder deposition for rapid manufacturing, San Antonio, Texas, USA, 2002, pp. 195-202.

14 Cho, W., Sachs, E. M., and Patrikalakis, N. M. Local composition control in solid freeform fabrication. Invited paper in Rapid Prototyping, quarterly of the Rapid Prototyping Association of the Society of Manufacturing Engineers, 7(2), 1-5.

15 Beal, V. E., Erasenthiran, P., Hopkinson, N., Dickens, P., and Ahrens, C. H. Fabrication of x-graded $\mathrm{H} 13$ and $\mathrm{Cu}$ powder mix using high power pulsed Nd:YAG laser. Proceedings of Solid freeform fabrication symposium, Austin, Texas, USA, 2004.

16 Matweb. AISI Type H13 Hot Work Tool Steel, air or oil quenched from $995-1025^{\circ} \mathrm{C}$, available online at http://www.matweb.com (accessed February 2005). 
17 Matweb. Copper, Cu; annealed, cold drawn and coldworked, available online at http://www.matweb.com (accessed February 2005).

18 Harris, R. A., Fouchal, F., Hague, R. J. M., and Dickens, P. Quantifying part irregularities and subsequent morphology manipulation in stereolithography plastic injection moulding. Plastics Rubbers Composites, 2004, 33(2/3), 92-98.

19 Incropera, F. P. and DeWitt, D. P. Fundamentals of heat and mass transfer, 3rd edition, 1990 (Wiley, New York).

20 Huntsman. RenShape: Stereolithography Materials: SL 7580, available online at http://www.huntsman. com/renshape (accessed February 2005).

21 Matweb. Overview - polypropylene, molded, available online at http://www.matweb.com (accessed February 2005).

22 German, R. M. Powder metallurgy science, 2nd edition, 1994, p. 472 (MPIF, New Jersey).

23 Osprey Metal Powders. Microfine powder - H13 and OHFC Cu datasheets, available online at http://www. ospreymetals.co.uk (accessed November 2003).

24 Potsch, G. and Michaeli, W. Injection moulding: an introduction, 1995 (Carl Hanser Verlag, Munich, Germany).

25 Marinelli, A. L. and Bretas, R. E. S. Blends of polypropylene resins with a liquid crystalline polymer: I-isothermal crystallization. J. Appl. Polymer Sci., 2003, 87(6), 916-930.

\section{APPENDIX}

\section{Notation}

A area

$c_{\mathrm{p}} \quad$ specific heat

$E \quad$ variation (balance) of energy

$\dot{E}_{\text {gen }} \quad$ generated energy in the volume control

$\dot{E}_{\text {in }} \quad$ energy flux entering the volume control

$\dot{E}_{\text {out }} \quad$ lost energy from the volume control

$\Delta H \quad$ heat of fusion for PP sample

$\Delta H_{100 \%}$ heat of fusion for 100 per cent crystalline PP

$k$ heat conduction coefficient

$q^{\prime \prime} \quad$ heat fluxes

$t \quad$ time

$T \quad$ temperature

$T_{\mathrm{tc}} \quad$ thermocouple temperature

$T_{\text {is }} \quad$ insert surface temperature

$V \quad$ volume fraction or volume

$x \quad$ axis of the direction of the heat flux

X\% degree of crystallinity

$\alpha \quad$ material phase

$\beta \quad$ material phase

$\varepsilon \quad$ equivalent property

$\rho \quad$ density 